\title{
THE ECONOMICS OF CLIMATE CHANGE
}

Lawrence H. Goulder

William A. Pizer

Working Paper 11923 


\title{
NBER WORKING PAPER SERIES
}

\section{THE ECONOMICS OF CLIMATE CHANGE}

Lawrence H. Goulder

William A. Pizer

Working Paper 11923

http://www.nber.org/papers/w11923

\author{
NATIONAL BUREAU OF ECONOMIC RESEARCH \\ 1050 Massachusetts Avenue \\ Cambridge, MA 02138 \\ January 2006
}

This paper is forthcoming as a chapter in The New Palgrave Dictionary of Economics, $2^{\text {nd }}$ edition, edited by Steven Durlauf and Lawrence Blume. The authors gratefully acknowledge very helpful comments on earlier drafts by Kenneth Arrow, Steven Durlauf, Raymond Kopp, Richard Morgenstern, Robert Stavins, and Roberton Williams III. The views expressed herein are those of the author(s) and do not necessarily reflect the views of the National Bureau of Economic Research.

(C2006 by Lawrence H. Goulder and William A. Pizer. All rights reserved. Short sections of text, not to exceed two paragraphs, may be quoted without explicit permission provided that full credit, including () notice, is given to the source. 
The Economics of Climate Change

Lawrence H. Goulder and William A. Pizer

NBER Working Paper No. 11923

January 2006

JEL No. D62, H23, N50, Q20

\begin{abstract}
Global climate change poses a threat to the well-being of humans and other living things through impacts on ecosystem functioning, biodiversity, capital productivity, and human health. This paper briefly surveys recent research on the economics of climate change, including theoretical insights and empirical findings that offer guidance to policy makers. Section 1 frames the climate change problem and indicates the ways that economic research can address it. Section 2 describes approaches to measuring the benefits and costs associated with reducing greenhouse gas emissions. In Section 3 we discuss the implications of uncertainty for the timing and stringency of policies to address possible climate change. We then present issues related to policy design, including instrument choice (Section 4), flexibility (Section 5), and international coordination (Section 6). The final section offers general conclusions.

Lawrence H. Goulder

Department of Economics

Landau Economics Building

Stanford University

Stanford, CA 94305

and NBER

goulder@stanford.edu

William A Pizer

Resources for the Future

1616 P Street, NW

Washington, DC 20036

pizer@rff.org
\end{abstract}




\title{
The Economics of Climate Change*
}

\author{
Lawrence H. Goulder \\ Stanford University, Resources for the Future, and NBER \\ William A. Pizer \\ Resources for the Future
}

November 2005

\section{Introduction}

The prospect of global climate change has emerged as a major scientific and public policy issue. Scientific studies indicate that accumulated carbon dioxide emitted from the burning of fossil fuels, along with contributions from other human-induced greenhouse gas emissions, are leading to warmer surface temperatures. Possible current-century consequences of this temperature increase include increased frequency of extreme temperature events (such as heat waves), heightened storm intensity, altered precipitation patterns, sea level rise, and reversal of ocean currents. These changes, in turn, can have significant impacts on the functioning of ecosystems, the viability of wildlife, and the wellbeing of humans.

There is considerable disagreement within and among nations as to what policies, if any, should be introduced to mitigate and perhaps prevent climate change and its various impacts. Despite the disagreements, in recent years we have witnessed the gradual emergence of a range of international and domestic climate-change policies, including emissions trading programs, emissions taxes, performance standards, and technologypromoting programs.

Beginning with William Nordhaus's (1982) "How Fast Shall We Graze the Global Commons?" climate-change economics has focused on diagnosing the economic underpinnings of climate change and offering positive and normative analyses of policies to confront the problem. While overlapping with other areas of environmental economics, it has a unique focus because of distinctive features of the climate problem - including the long time-scale, the extent and nature of uncertainties, the international scope of the issue, and the uneven distribution of policy benefits and costs across space and time.

In our discussion of the economics of climate change, we begin with a brief account of alternative economic approaches to measuring the benefits and costs associated with

\footnotetext{
*This paper is forthcoming as a chapter in The New Palgrave Dictionary of Economics, $2^{\text {nd }}$ edition, edited by Steven Durlauf and Lawrence Blume. The authors gratefully acknowledge very helpful comments on earlier drafts by Kenneth Arrow, Steven Durlauf, Raymond Kopp, Richard Morgenstern, Robert Stavins, and Roberton Williams III.
} 
reducing greenhouse gas emissions (Section 2), followed by a discussion of uncertainties and their consequences (Section 3). We then present issues related to policy design, including instrument choice (Section 4), flexibility (Section 5), and international coordination (Section 6). The final section offers general conclusions.

\section{Assessing the Benefits and Costs of Climate Change Mitigation}

\section{a. Climate change damages and mitigation benefits}

As noted, the potential consequences of climate change include increased average temperatures, greater frequency of extreme temperature events, altered precipitation patterns, and sea level rise. These biophysical changes affect human welfare. While the distinction is imperfect, economists divide the (often negative) welfare impacts into two main categories: market and non-market damages.

Market damages. As the name suggests, market damages are the welfare impacts stemming from changes in prices or quantities of marketed goods. Changes in productivity typically underlie these impacts. Often researchers have employed climate-dependent production functions to model these changes, specifying wheat production, for example, as a function of climate variables such as temperature and precipitation. In addition to agriculture, this approach has been applied in other industries including forestry, energy services, water utilities and coastal flooding from sea-level rise (see, for example, Smith and Tirpak 1989; Yohe et al. 1996; Mansur et al. 2005).

The production function approach tends to ignore possibilities for substitution across products, which motivates an alternative, hedonic approach (see, for example, Mendelsohn et al. 1994, and Schlenker et al. forthcoming;). Applied to agriculture, the hedonic approach aims to embrace a wider range of substitution options, employing cross-section data to examine how geographical, physical, and climate variables are related to the prices of agricultural land. Assuming that crops are chosen to maximize rents, that rents reflect the productivity of a given plot of land relative to that of marginal land, and that land prices are the present value of land rents, the impact of climate variables on land prices is an indicator of their impact on productivity after allowing for crop-substitution.

Non-market damages. Non-market damages include the direct utility loss stemming from a less hospitable climate, as well as welfare costs attributable to lost ecosystem services or lost biodiversity. For these damages, revealed-preference methods face major challenges here because non-market impacts may not leave a "behavioral trail" of induced changes in prices or quantities that can used to determine welfare changes. The loss of biodiversity, for example, does not have any obvious connection with price changes or observable demands. Partly because of the difficulties of revealed-preference approaches in this context, researchers often employ stated-preference or interview techniques - most notably the contingent valuation method - to assess the willingness to pay to avoid non-market damages. (See, for example, Smith 2004.) 


\section{b. Cost assessment}

The costs of avoiding emissions of carbon dioxide, the principal greenhouse gas, depend on substitution possibilities on several margins: the ability to substitute across different fuels (which release different amounts of carbon dioxide per unit of energy), to substitute away from energy in general in production, and to shift away from energyintensive goods. The greater the potential for substitution, the lower the costs of meeting a given emissions-reduction target.

Applied models have taken two main approaches to assessing substitution options and costs. One approach employs "bottom-up" energy technology models with considerable detail on the technologies of specific energy processes or products (for example, Barretto and Kypreos 2004). The models tend to concentrate on one sector or a small group of sectors and offer less information on abilities to substitute from energy in general, or on how changes in the prices of energy-intensive goods affect intermediate and final demands for those goods.

The other approach employs "top down" economy-wide models, which include but are not limited computable general equilibrium (CGE) models (see, for example, Jorgenson and Wilcoxen 1996; and Conrad 2002). An attraction of these models is their ability to trace relationships between fuel costs, production methods, and consumer choices throughout the economy in an internally consistent way. However, they tend to include much less detail on specific energy processes or products. Substitution across fuels is generally captured through smooth production functions, rather than through explicit attention to alternative discrete processes. In recent years, attempts have been made to reduce the gap between the two types of models. Bottom-up models have gained scope, and top-down models have incorporated greater detail. (See, for example, McFarland et al. 2004.)

Because climate depends on the atmospheric stock of greenhouse gases, and because for most gases the residence times in the atmosphere are hundreds (and in some cases, thousands) of years, climate change is an inherently long-term problem and assumptions about technological change are particularly important. The modeling of technological change has advanced significantly beyond the early tradition that treated technological change as exogenous. Several recent models allow the rate or direction of technological progress to respond endogenously to policy interventions. Some models focus on $R \& D$ based technological change, incorporating connections between policy interventions, incentives to research and development, and advances in knowledge. (See, for example, Goulder and Schneider (1999), Nordhaus (2002), Buonanno et al. (2003), and Popp (2004).) Others emphasize learning-by-doing-based technological change where production cost falls with cumulative output, in keeping with the idea that cumulative output is associated with learning (for example, Manne and Richels (2004)). Allowing for policy-induced technological change tends to yield lower (and sometimes significantly lower) assessments of the costs of reaching given emissions-reduction targets relative to models in which technological change is exogenous. 


\section{c. Integrated assessment}

While the cost models described above are useful for evaluating the costeffectiveness of alternative policies to achieve a given emissions target, the desire to relate costs to mitigation benefits (avoided damages) has spawned the development of integrated assessment models. These models link greenhouse gas emissions, greenhouse gas concentrations, and changes in temperature or precipitation, and they consider how these changes feed back on production and utility. Many of the integrated assessment models are optimization models that solve for the emissions time-path that maximizes net benefits, in some cases under constraints on temperature or concentration (see, for example, Nordhaus 1994).

\section{Dealing with Uncertainty}

The uncertainties about both the costs and benefits from reduced climate change are vast. In a recent meta-analysis examining 28 studies' estimated benefits from reduced climate change (Tol 2005), the 90-percent confidence interval for the benefit estimates ranged from $-\$ 10$ to $+\$ 350$ per ton of carbon, with a mode of $\$ 1.50$ per ton. On the cost side, a separate study found marginal costs of between $\$ 10$ and $\$ 212$ per ton of carbon for a 10 percent reduction in 2010 (Weyant and Hill 1999).

\section{a. Uncertainty and the stringency of climate policy}

Increasingly sophisticated numerical models have attempted to deal explicitly with these substantial uncertainties regarding costs and benefits. Some provide an uncertainty analysis using Monte Carlo approaches, providing either a range of consequences for a given policy or a range of optimal policies. Others explicitly optimize over uncertain outcomes, typically finding justification for a more aggressive climate policy than would emerge from a deterministic analysis. Nordhaus (1994) employs an integrated climate-economy model to compare the optimal carbon tax in a framework with uncertain parameter values with the optimal tax when parameters are set at their central values. In this application, an uncertainty premium arises: the optimal tax is more than twice as high in the former case than in the latter, and the optimal amount of abatement is correspondingly much greater. The higher optimal tax could in principle be due to uncertainty about any parameter whose relationship with damages is convex, thus yielding large downside risks relative to upside risks. In the Nordhaus model, the higher optimal tax stems primarily from uncertainty about the discount rate (Pizer 1999).

\section{b. The choice of discount rate under uncertainty}


The importance of the discount rate arises because greenhouse gases persist in the atmosphere for a century or more, and therefore mitigation benefits must be measured on dramatically different time-scales from those of ordinary environmental problems. A prescriptive approach links the discount rate to subjective judgments about intergenerational equity as indicated by a pure social rate of time-preference (see, for example, Arrow et al. 1996). A descriptive approach relates the discount rate to future market interest rates. Under both approaches, significant uncertainties surround the discount rates. Recent work by Weitzman (1998) points out that a rate lower than the expected value should be employed in the presence of such uncertainty, a reflection of the relationships among the discount factor, the discount rate, and the time-interval over which discounting applies. Put simply, the discount factor $e^{-r t}$ is an increasingly convex function of the interest rate $r$ as the period of discounting $t$ increases. This implies that in the presence of uncertainty the certaintyequivalent discount rate is lower than the expected value of the discount rate: that is, $\ln \left(\mathrm{E}\left[e^{-r t}\right]\right) / t<\mathrm{E}[r]$. The difference between the appropriate, certainty-equivalent rate and the expected value of the discount rate widens the longer is the time horizon. While Weitzman focuses on a single uncertain rate, Newell and Pizer (2003a) show that under reasonable specifications of uncertainty about the evolution of future market rates, this approach doubles the expected marginal benefits from future climate change mitigation compared with the estimated benefits from an analysis that uses only the current rate.

\section{c. Act today or wait for better information?}

In addition to concerns about convexity and valuation, uncertainty raises important questions about whether and how much to embark on mitigation activities now versus waiting until at least some uncertainty is resolved. Economic theory suggests that in the absence of fixed costs and irreversibilities, society should mitigate (today) to the point where expected marginal costs and benefits are equal. Yet climate change inherently involves fixed costs and irreversible decisions both on the cost side, in terms of investments in carbon-free technologies, and on the benefit side, in terms of accumulated emissions. These features can lead to more intensive action, or to inaction, depending on the magnitude of their respective sunk values (Pindyck 2000). Despite the ambiguous theory, empirically calibrated analytical and numerical models tend to recommend initiating reductions in emissions in the present, reflecting initially negligible marginal cost and non-negligible environmental benefits (Manne and Richels 2004; Kolstad 1996).

\section{The Choice of Instrument for Climate-Change Policy}

Policy makers can consider a range of potential instruments for promoting reductions in emissions of greenhouse gases. Alternatives include emissions taxes, abatement subsidies, emissions quotas, tradable emissions allowances, and performance standards. Policy makers also can choose whether to apply a given instrument to emissions directly (as with an emissions trading program) or instead to pollution-related goods or services (as with a fuel tax or technology subsidy). 
Initial economic analyses of climate-change policy tended to focus on a carbon tax because it was relatively easy to model and implement. This is a tax on fossil fuels - oil, coal, and natural gas - in proportion to the carbon content of the fuels. Because combustion of fossil fuels or their refined fuel products leads to carbon dioxide $\left(\mathrm{CO}_{2}\right)$ emissions proportional to carbon content, a carbon tax is effectively a tax on $\mathrm{CO}_{2}$ emissions. In the simplest analysis, a carbon tax set equal to the marginal climate-related damage from carbon combustion would be efficiency-maximizing. However, in more complex analyses - where additional dimensions such as uncertainty, other market failures, and distributional impacts are taken into account - the superiority of such a carbon tax is no longer assured. We now consider these other dimensions and their implications for instrument choice.

\section{a. Prices (taxes) vs. quantities (tradable allowances) in the presence of uncertainty}

Theoretical and empirical work by Kolstad (1996) and Newell and Pizer (2003b) suggests that the marginal benefit (avoided damage) schedule for emissions reductions is relatively flat. Weitzman's (1974) seminal analysis indicates that under these circumstances, expected welfare losses are smaller when a price-based instrument like a carbon tax is employed, as opposed to a quantity-based instrument like emissions quotas or a system of tradable emissions allowances. That is, it is preferable to let levels of emissions remain uncertain (which is the result under a tax) than to let the marginal price of emissionsreductions remain uncertain (which is the result under a quota). Despite these economic welfare arguments, and recent work on hybrid approaches (Pizer 2002), many environmental advocates prefer the quantity-based approach precisely because it removes uncertainty about the level of emissions.

\section{b. Fiscal impacts and instrument choice}

A second issue stems from interactions with the tax system and the potential for policies such as carbon taxes and auctioned permits to generate revenues. A number of studies show that using such revenues to finance reductions in pre-existing distortionary taxes on income, sales, or payroll can achieve given environmental targets at lower cost perhaps substantially lower cost - than other policies (see, for example, Goulder et al. 1999, Parry et al. 1999, and Parry and Oates 2000). Therefore, carbon taxes and auctioned permit programs that employ their revenues this way will lower the excess burden from prior taxes, giving them a significant cost-advantage. Correspondingly, subsidies to emissionsreductions or to new, "clean" technologies will have a cost-disadvantage associated with the need to raise distortionary taxes to finance these policies.

\section{c. Distributional considerations}

Despite these attractions of revenue-raising policies such as carbon taxes and auctioned tradable allowance systems, trading programs with freely distributed permits have gained more popularity among policy makers. For example, while the United Kingdom had, 
and New Zealand has planned, a carbon tax (both with exceptions for heavy industry), the European Union and Canada have or have planned trading programs where tradable permits are freely distributed, in line with virtually all conventional pollution trading programs in the United States.

The politics may reflect different regulatory burdens under a system of freely allocated allowances, as compared with a system with auctioned allowances. Under both types of emissions permit system, profit-maximizing firms will find it in their interest to raise output prices based on the new, non-zero cost associated with carbon emissions. If the allowances are given out free, firms can retain rents associated with the higher output prices, and this offsets other compliance costs. In contrast, if the allowances are auctioned, firms do not capture these rents. Thus, firms bear a considerably smaller share of the regulatory burden in the case of freely allocated permits. Indeed, Bovenberg and Goulder (2001) show that freely allocating all carbon permits to U.S. fossil fuel suppliers generally will cause those firms to enjoy higher profits than in the absence of a permit system; and freely allocating less than a fifth of the permits may be sufficient to keep profits from falling. These considerations reveal a potential trade-off between efficiency and political feasibility: the revenue-raising policies (taxes and auctioned permits) are the most cost-effective, while the non-revenue-raising policies (freely-distributed permits) have distributional consequences that may reduce political resistance.

\section{d. Emissions instruments vs. technology instruments}

As noted in the cost discussion, the long-term nature of the climate-change problem makes technological change a central issue in policy considerations. Economic analysis suggests that both "direct emissions policies" and "technology-push policies" are justified on efficiency grounds to correct two distinct market failures. Direct emissions policies (emissions trading or taxes) gain support from the fact that combustion of fossil fuels and by other greenhouse-gas-producing activities generate negative externalities in the form of climate-change-related damages. Technology-push policies (technology and R\&D incentives) gain support from the fact that not all of the social benefits from the invention of a new technology can be appropriated by the inventor. The latter argument applies to research and development more generally, and is especially salient if the first market-failure is not fully corrected (Fischer 2004a). Numerical assessments reveal substantial cost-savings from combining the two types of policy (Fischer and Newell 2005; Schneider and Goulder 1997).

\section{Policy Designs to Enhance Flexibility}

The previous discussion indicates that no single instrument is best along all important policy dimensions, including cost uncertainty, fiscal interactions, distribution, and technology development. A further issue in policy choice is how to give regulated firms or nations the flexibility to seek out mitigation opportunities wherever and whenever they are cheapest. For both price- and quantity-based policies, flexibility is enhanced through broad 
coverage: specifically, by including as many emissions sources in the program as possible and by providing opportunities for regulated sources to offset their obligations through relevant activities outside the program. For quantity-based programs, flexibility can also be promoted through provisions allowing trading of allowances across gases, time, and national boundaries. Such flexibility is automatically provided by price-based programs simply because they involve no quantitative emissions limits. Importantly, as quantity-based programs provide these additional dimensions of flexibility, they reduce the efficiency arguments for price-based policies in the face of uncertainty voiced in the preceding section by providing opportunities to adjust to idiosyncratic cost shocks across time, space, and industry (Jacoby and Ellerman 2004).

\section{a Flexibility over gases and sequestration}

So far we have focused almost exclusively on emissions of carbon dioxide from the burning of fossil fuels as both the cause of human-induced climate change and the object of any mitigation policy. Yet emissions of a number of other gases (as well as non-energy related emissions of carbon dioxide) contribute to the problem and possibly the solution, particularly in the short run. Models suggest that half of the reductions achievable at costs of \$5-10 per ton of carbon dioxide equivalent arise from gases other than carbon dioxide. In addition, carbon sequestration can be part of the solution. Biological sequestration (e.g., through afforestation) has been cited as a particularly inexpensive response to climate change (Sedjo 1995; Richards and Stavins 2005). Geological sequestration (e.g., injection into depleted oil or gas reservoirs) represents a very expensive proposition now, but could be an important component of a long-term policy solution if costs decline (Newell and Anderson 2004).

Four issues can complicate the inclusion of these activities: monitoring, baselines, comparability, and, in some cases, liability. First, some of these sources are fugitive emissions that are difficult to monitor at any point in the product cycle. Second, some activities, especially those involving fugitive emissions, are often left unregulated but allowed to enter as "offsets," requiring a counterfactual baseline against which actual emissions levels can be measured. Fischer (2004b) evaluates various approaches to defining project baselines.

Third, a problem of comparability arises with non- $\mathrm{CO}_{2}$ gases because it is necessary to determine relative prices among greenhouse gases in a market-based program. As a theoretical matter, the relative price between a ton of current emissions of two gases should be the ratio of the present value of damages from these emissions (Schmalensee 1993). In practice, it is difficult to apply this formula because it requires a great deal of information about the damages and because it calls for time-varying trading ratios (Reilly et al. 2001), which implies significant administrative burdens. Under the Kyoto Protocol and the EU Emissions Trading Scheme, one set of trading ratios is used at all times, and the ratios are calculated by determining the ratio of warming impacts over a 100-year horizon beginning with the present time. 
Finally, a liability issue arises with regard to sequestration. For both biologically and geologically sequestered carbon, a key question is who should be held liable for carbon dioxide that is released accidentally or otherwise.

\section{b. Flexibility over time}

While price policies naturally allow emissions to rise and fall in response to shocks over time, quantity-based policies must explicitly address the question of whether regulated sources can bank unused allowances for future use or, in some cases, borrow them from future allocations. In the climate change context, merely shifting emissions across time, versus allowing accumulated emissions to vary, holds the environment harmless because climate consequences are generally due to accumulated concentrations, not annual emissions (Roughgarden and Schneider 1999, discuss the possibility of dependence on both accumulated concentrations and the rate of accumulation). Such shifts across time might reflect either a more efficient choice of timing in response to capital turnover and technological progress (Wigley et al. 1996), or an attempt to ameliorate cost-shocks (Williams 2002; Jacoby and Ellerman 2004). The rate of exchange between present and future emissions allowances need not be unity: Kling and Rubin (1997) show that the optimal rate at which banked allowances translate across periods should reflect the expected trend in marginal mitigation benefits, the interest rate, and decay rate of the accumulated gas.

\section{c. Flexibility over location}

The defining feature of the climate-change problem may be its intrinsically global nature. Greenhouse gases tend to disperse themselves uniformly around the globe. As a result, the climate consequences of a ton of emissions of a given greenhouse gas do not depend on the location of the source, either within or across national borders, and shifts in emissions across locations do not change global climate impacts. Under these circumstances, economic efficiency calls for making market-based systems as geographically broad as possible. It supports federal over regional policies, and international coordination over idiosyncratic domestic responses.

\section{International Policy Initiatives and Coordination}

International coordination is both crucial and exceptionally difficult to achieve. Studies indicate that the economic and social impacts of climate change would be distributed very unevenly across the globe, with the prospect of large damages to several nations in the tropics coupled with the potential for benefits to some countries in the temperate zones (see, for example, Tol 2005 and Mendelsohn 2003). This uneven distribution makes achieving international coordination especially difficult. 
The Kyoto Protocol is the first significant international effort to reduce greenhouse gas emissions. It assigns emissions limits to participating industrialized countries for 20082012, but offers flexibility in allowing these countries to alter their limits by buying or selling emissions allowances from other industrialized countries or by investing in projects that lead to emissions-reductions in developing countries. The importance of these flexibility mechanisms for dramatically lowering compliance costs in this international setting is well documented (Weyant and Hill 1999).

The Protocol has been criticized on the grounds that it imposes overly stringent emissions-reduction targets and lacks a longer-term vision for action. In addition, a core feature of the Protocol-legally-binding emissions limits - has been challenged on the grounds that such limits are not self-enforcing, an arguably necessary attribute in a world of sovereign nations (Barrett 2003). Some argue that the Protocol's project-based mechanisms for encouraging (but not requiring) emissions-reductions in developing countries are highly bureaucratic and cumbersome, consistent with our earlier comments about project-based programs more generally. These criticisms have led to considerable research considering the Kyoto structure and comparing it with various alternative international approaches. Aldy et al. (2003) summarize more than a dozen alternatives, which include an international carbon tax and international technology standards.

A further major criticism is that the Protocol imposes no mandatory emissions limits on developing countries, which collectively are expected to match industrialized countries in emissions of greenhouse gases by 2035 . The desire to promote greater participation by developing countries, and well as to involve the United States in the international effort, has motivated considerable research examining, within a game-theoretic framework, the requirements for broader participation and for stable international coalitions. (See, for example, Carraro 2003, Hoel and Schneider 1997, and Tulkens 1998.)

\section{Conclusions}

Climate-change economics has produced new methods for evaluating environmental benefits, for determining costs in the presence of various market distortions or imperfections, for making policy choices under uncertainty, and for allowing flexibility in policy responses. Although major uncertainties remain, it has helped generate important guidelines for policy choice that remain valid under a wide range of potential empirical conditions. It has also helped focus empirical work by making clear where better information about key parameters would be most valuable.

Clearly, many theoretical and empirical questions remain unanswered. We suggest (with some subjectivity) that there is a particularly strong need for advances in the integration of emissions policy and technology policy, in defining baselines that determine the extent of offset activities outside a regulated system, and in fostering international cooperation. 
From 2003 until 2030, the world is poised to invest an estimated \$16 trillion in energy infrastructure, with annual carbon dioxide emissions estimated to rise by 60 percent. How well economists answer important remaining questions about climate change could have a profound impact on the nature and consequences of that investment.

\section{References}

Aldy, Joseph E., Scott Barrett, and Robert N. Stavins. 2003. Thirteen Plus One: A Comparison of Alternative Climate Policy Architectures. Climate Policy 3 (4):373397.

Arrow, K.J., W.R. Cline, K.-G. Maler, M. Munasinghe, R. Squitieri, and J.E. Stiglitz. 1996. Intertemporal Equity, Discounting and Economic Efficiency. In Climate Change 1995 - Economic and Social Dimensions of Climate Change, edited by J. P. Bruce, H. Lee and E. F. Haites. Cambridge, UK: Cambridge University Press.

Barrett, Scott. 2003. Environment and Statecraft. New York, NY: Oxford University Press. Barretto, L., and S. Kypreos. 2004. Emissions trading and technology deployment in an energy-system 'bottom-up' model with technological learning. European Journal of Operations Research 158 (1):243-261.

Bovenberg, A. Lans, and Lawrence H. Goulder. 2001. Neutralizing the Adverse Industry Impacts of $\mathrm{CO}_{2}$ Abatement Policies: What Does It Cost? In Behavioral and Distributional Effects of Environmental Policies, edited by C. Carraro and G. Metcalf. Chicago: University of Chicago Press.

Buonanno, P., C. Carraro, and EM. Galeotti. 2003. Endogenous induced technical change and the costs of Kyoto. Resource and Energy Economics 25 (1):11-34.

Carraro, C., ed. 2003. The Endogenous Formation of Economic Coalitions. Northhampton, MA: Elgar.

Conrad, Klaus. 2002. Computable General Equilibrium Models in Environmental and Resource Economics. In The International Yearbook of Environmental and Resource Economics 2002-2003, edited by T. Tietenberg and H. Folmer. Cheltenham, UK: Edward Elgar.

Fischer, Carolyn. 2004a. Emission pricing, spillovers, and public investment in environmentally friendly technologies. Washington, DC: Resources for the Future. . 2004b. Project-based mechanisms for emissions reductions: balancing trade-offs with baselines. Energy Policy 33 (14):1807-1823.

Fischer, Carolyn, and Richard Newell. 2005. Environmental and Technology Policies for Climate Mitigation, working paper. Washington: Resources for the Future.

Goulder, Lawrence H., Ian Parry, Roberton Williams III, and Dallas Burtraw. 1999. The Cost-Effectiveness of Alternative Instruments for Environmental Protection in a Second-Best Setting. Journal of Public Economics 72 (3):329-360.

Goulder, Lawrence H., and Stephen L. Schneider. 1999. Induced Technological Change and the Attractiveness of $\mathrm{CO}_{2}$ Emissions Abatement Policies. Resource and Energy Economics 21:211-253.

Hoel, M., and K. Schneider. 1997. Incentives to Participate in an International Environmental Agreement. Environment and Resource Economics 9:153-170. 
Jacoby, Henry D., and A. Denny Ellerman. 2004. The Safety Valve and Climate Policy. Energy Policy 32 (4):481-491.

Jorgenson, Dale W., and Peter J. Wilcoxen. 1996. Reducing U.S. Carbon Emissions: An Econometric General Equilibrium Assessment. In Reducing Global Carbon Dioxide Emissions: Costs and Policy Options, edited by D. Gaskins and J. Weyant. Stanford, Calif.: Energy Modeling Forum, Stanford University.

Kolstad, Charles D. 1996. Learning and stock effects in environmental regulation: the case of greenhouse gas emissions. Journal of Environmental Economics and Management 31 (1):1-18.

Manne, Alan S., and R. Richels. 2004. The impacts of learning-by-doing on the timing and costs of $\mathrm{CO}_{2}$ abatement. Energy Economics 26 (4):603-619.

Mansur, Erin, Robert Mendelsohn, and Wendy Morrison. 2005. A Discrete-Continuous Choice Model of Climate Change Impacts on Energy. New Haven, CT: Yale School of Forestry and Environmental Studies.

McFarland, J. R., J. M. Reilly, and H. J. Herzog. 2004. Representing energy technologies in top-down economic models using bottom-up information. Energy Economics 26 (4):685-707.

Mendelsohn, Robert. 2003. Assessing the market damages from climate change. In Global Climate Chnage: The Science, Economics, and Politics. Cheltenham, UK: Edward Elgar.

Mendelsohn, Robert, William D. Nordhaus, and Daigee Shaw. 1994. The Impact of Global Warming on Agriculture: A Ricardian Analysis. American Economic Review 84 (4).

Newell, Richard G., and Soren T. Anderson. 2004. Prospects for carbon capture and storage technology. Annual Review of Environment and Resources 29:109-142.

Newell, Richard, and William Pizer. 2003a. Discounting the distant future: how much do uncertain rates increase valuations. Journal of Environmental Economics and Management 46 (1):52-71.

- 2003b. Regulating Stock Externalities Under Uncertainty. Journal of Environmental Economics and Management 45:416-432.

Nordhaus, William D. 1994. Managing the Global Commons. Cambridge: MIT Press.

- 2002. Modeling Induced Innovation in Climate-Change Policy. In Technological Change and the Environment, edited by A. Grübler, N. Nakicenovic and W. D. Nordhaus. Washington: Resources for the Future.

Parry, Ian, Roberton C. Williams III, and Lawrence H. Goulder. 1999. When can carbon abatement policies increase welfare? The fundamental role of distorted factor markets. Journal of Environmental Economics and Management 37(1):52-84.

Parry, Ian, and Wallace E. Oates. 2000. Policy Analysis in the Presence of Distorting Taxes. Journal of Policy Analysis and Management 19:603-614.

Pindyck, Robert S. 2000. Irreversiblities and the Timing of Environmental Policy. Resource and Energy Economics 22:233-259.

Pizer, William A. 1999. Optimal choice of policy instrument and stringency under uncertainty: the case of climate change. Resource and Energy Economics 21 (34):255-287.

2002. Combining price and quantity controls to mitigate global climate change. Journal of Public Economics 85 (3):409-434. 
Popp, David. 2004. ENTICE: Endogenous technological change in the DICE model of global warming. Journal of Environmental Economics and Management 48 (1): 74268.

Reilly, John, Mustafa Babiker, and Monika Mayer. 2001. Comparing Greenhouse Gases. Cambridge, MA: MIT Joint Center for the Science and Policy of Global Change.

Richards, K.R., and R. Stavins. 2005. The cost of U.S. forest-based carbon sequestration. Arlington, VA: Pew Center on Global Climate Change.

Roughgarden, Tim, and Stephen H. Schneider. 1999. Climate Change Policy: Quantifying Uncertainties for Damage and Optimal Carbon Taxes. Energy Policy 27 (7).

Schlenker, Wolfram, Anthony Fisher, and Michael Hanemann. forthcoming. Will U.S. Agriculture Really Benefit from Global Warming. American Economic Review.

Schmalensee, Richard. 1993. Comparing Greenhouse Gases for Policy Purposes. Energy Journal 14 (1):245-255.

Schneider, Stephen H., and Lawrence H. Goulder, 1997. Achieving low-cost emissions targets. Nature 389, September.

Sedjo, Roger. 1995. The Economics of Managing Carbon via Forestry: An Assessment of Existing Studies. Environment and Resource Economics 6 (2):139-165.

Smith, Joel B., and Dennis A. Tirpak. 1989. The Potential Effects of Global Climate Change on the United States: Report to Congress. Washington, DC: U.S. Environmental Protection Agency.

Smith, V. Kerry. 2004. Fifty Years of Contingent Valuation. In The International Yearbook of Environmental and Resource Economics 2004-2005, edited by T. Tietenberg and H. Folmer. Cheltenham, UK: Edward Elgar.

Tol, Richard S.J. 2005. The marginal damage costs of carbon dioxide emissions: an assessment of the uncertainties. Energy Policy 33:2064-2074.

Tulkens, H. 1998. Cooperation Versus Free Riding in International Environmental Affairs: Two Approaches. In Game Theory and the Environment, edited by N. Hanley and H. Folmer. Cheltenham, UK: Edward Elgar.

Weitzman, Martin L. 1974. Prices vs. Quantities. Review of Economic Studies 41 (4):477491.

Weyant, John P., and Jennifer Hill. 1999. The Costs of the Kyoto Protocol: A Multi-Model Evaluation, Introduction and Overview. Energy Journal Special Issue.

Wigley, T.M.L., R. Richels, and J.A. Edmonds. 1996. Economic and environmental choices in the stabilization of atmospheric $\mathrm{CO}_{2}$ concentrations. Nature 379:240-243.

Williams, Roberton III. 2002. Prices vs. Quantities vs. Tradable Quantities, working paper. Austin: Department of Economics, University of Texas.

Yohe, G.W., H. Ameden, P. Marshall, and J. Neumann. 1996. The economic cost of greenhouse-induced sea-level rise for developed property in the United States. Climatic Change 32 (387-410). 